\title{
INFECÇõES HOSPITALARES NO MUNICÍPIO DE ARARAQUARA, SP (BRASIL)
}

Clara Pechmann Mendonça *

Mariza Landgraf **

Paulo Roberto Natalino **

Suzana Debora Ruff***

\section{RSPU-B/318}

MendonçA, C.P. et al. - Infeccōes hospitalares no municipio de Araraquara, SP (Brasil). Rev. Saúde públ., S. Paulo, 10:239-52, 1976.

Resumo: Foi demonstrada a etiologia das infecções adquiridas em hospitais da cidade de Araraquara, S. Paulo, Brasil, verificando-se o comportamento das bactérias isoladas frente a 10 antimicrobianos. A metodologia bacteriológica seguida conduziu à especiação bacteriana, com exceção do estafilococos que foi identificado através da fagotipagem. Dos 171 processos infecciosos, adquiridos nos hospitais no periodo de setembro de 1974 a maio de 1975, foram isolados 211 microrganismos, sendo $73,0 \%$ de bactérias Gram negativas e $27,0 \%$ de bactérias Gram positivas. Verificou-se um alto nivel de resistência à maioria dos antibióticos. As bactérias Gram negativas apresentaram menor resistencia à Gentamicina (22,2\%), enquanto as Gram positivas apresentaram menor resistência à Cefalotina (17,7\%), à Fosfomicina (25,5\%) e à Gentamicina (29,4\%). Os resultados permitiram antever sérias dificuldades quanto à ação dos antimicrobianos sobre as bactérias, assim como a intensa disseminaçäo das bacterias Gram negativas, especialmente a Escherichia coli e as Pseudomonas.

UNITERmos: Infecções hospitalares, Araraquara (Brasil). Antibiograma.

As infecções adquiridas em hospitais têm sido objeto de estudo em todas as partes do mundo e, segundo Mc Namara e col. ${ }^{28}$, são consideradas inevitáveis, dentro de determinados limites.

Nos últimos anos, o número de publicações a respeito de infecções hospitalares tem aumentado grandemente e o problema assume característica mundial.
Em 1969, Martin ${ }^{25}$, propôs a criação de um Registro Nacional de Bacteriemias, nos EUA, por ter constatado a ocorrência de 50.000 óbitos em 250.000 casos de septicemias provocadas por infecções hospitalares. Admite esse autor, como provável, a proporção de 10 casos de infecção para cada mil admissões em hospital, con-

* Do Departamento de Ciências Patológicas e Microbiologia da Faculdade de Farmárcia e Odontologia de Araraquara (FFOA). Rua Expedicionários do Brasil, 1621 - Araraquara, $\mathrm{SP}-$ Brasil.

* Ex. Monitores do Departamento de Ciências Patológicas e Microbiologia da Faculdade de Farmácia e Odontologia de Araraquara.

*** Do Curso de Farmácia da Faculdade de Farmácia e Odontologia de Araraquara. 
IENDONCA. C. P. et al. - Infeçoes hospitalares no municipio de Araraquara, SP (Brasil). Rer. saude publ. S Paulo. 10.239-52. 1976.

cluindo que cerca de 609 dos casos são provocados por hactérias Gram negativas.

Reconhecemos que hoje as condições em quase todos os hospitais favorecem ainda mais a disseminação de microrganismos. O número de pacientes que se internam com infecçoes ou que adquirem processos infecciosos no decorrer da internação tem sido grande. Acreditamos gue uma série de causas concorra para esca situação: a) o mau estado geral dos pacientes acometidos frequentemente de doenças graves. degenerativas; b) as intervenções cirúrgicas de maior envergadura provocando queda no estado de saúde dos pacientes e oferecendo. conseqüentemente, maior possibilidade de penetracão e implantação de germes (Kessner e Lepper $=$; ; c) os tratamentos prolongados com antibióticos e corticoterápicos: d) a quimioterapia antineoplásica. a radioterapia e o uso. tanto intensivo como extensivo de cateterismo uretral e venoso, as endoscopias. e outros (Freid e Vosti ${ }^{15}$. Banks ${ }^{3}$ Baljinghton e cols. $\left.{ }^{2}\right)$. L'midificadores. rentiladores e outros aparelhos do equipamento de assistência respiratória também são os grandes colahoradores da disseminação e implantação de microrganismos. principalmente das Klebsiellas e I'seudomonas (Gardner e Smith ${ }^{16}$ ). Além disso. há nos Hospitais, o uso indiscriminado de antibióticos que concorrem para - aparecimento de mutantes resistentes. causando maior número de infecções hospitalares cruzadas (Williams e col.". Shallard e Williams ${ }^{42,49}$ ).

Durante longos anos. o estreptococo beta hemolítico (Rammelkamp e col. ${ }^{\circ}$ ) era o agente etiológico das infecções hospitalares. principalmente entre parturientes.

Atualmente são escassas as infecções hospitalares por esse germe. Em 1966. Mc Kee e col." referem-se a um surto. enrolvendo 11 pacientes, e Joble ${ }^{32}$ cita um surto em clínica dermatológica.
Após o aparecimento dos antibióticos. romeçaram a surơir. em maior número. as infeccooes provocadas por estafilococos e. de 1950 a 1965. alastraram-se pelo mundo todo. causando problemas graves para a humanidade.

Para Williams" a transmiscão de estafilococos em hospitais pode ser feita por ria aérea. sendo os portadores nasais os vrandes responsáveis pela dispersão das hactérias. Em estudos já realizados. verificamos que por númerosas vezes a transmissão fora feita de doente a doente.

Em 1968. Winton e Keay. estudando recém-natos. encontraram. no ar ambiente dos berçários. 0.r's de flora constituída de estafilococos e $0.15 c_{c}^{c}$ de hactérias Cram negativas. Ja superfície corporal das crianças encontraram 23\% de estafilococos e 4.7 'c de hactérias Gram negativas.

Pequignot e col. . Thohum e col. ". Dupont e Spink ${ }^{11}$. citam infecções hospitalares provocadas por hactérias Cram positivas e por Gram negativas. sendo que. entre estas. predominam as enterohactérias - as Pseudomonas.

À medida que os estafilococos foram adquirindo resistência aos antibióticos, a sua atuação parece que diminuiu e obserrou-se o aparecimento de maior número de infecçôes prorocadas por hactérias Gram negativas (Waisbren ". Tow "Spittel e Jichols ${ }^{4 \pi}$. Finland e col. ${ }^{21}$. Barrett e col. '. Mc Namara e col." Caswell e col." Thoburn e col. ${ }^{\text {in }}$.

Acredita-se que o uso dos antibióticos e quimioterápicos. utilizados no combate às estafilococias, tenha contribuído sohremaneira para a mudança etiológica dos processos infecciosos hospitalares e que tenha farorecido a multirresistência atualmente verificada (Hutzler e col. ${ }^{2 n}$. Stamm*1.

\footnotetext{
* Comunicasão pessoal.
} 
MENDONCA, C. P. et al. - Infecsões hospitalares no municipio de Araraquara, SP (Brasil). Rev. Saúde pribl., S Paulo, 10 239-52, 1976.

Neste estudo pretendemos demonstrar a etiologia das infecções adquiridas em hospitais da cidade de Araraquara, S.P., Brasil, verificando o seu comportamento frente a 10 antimicrobianos.

\section{MATERIAL E MÉTODOS}

O período de observação estendeu-se de setembro de 1974 a maio de 1975 , coletando-se material em dois hospitais gerais. Não foram considerados isoladamente, porquanto os resultados foram muito semelhantes, pois o corpo médico e o sistema de atendimento são praticamente o mesmo.

Foram coletados materiais de pacientes, quando o início dos processos infecciosos se dera, pelo menos, 48 horas após a internação. Consideraram-se como infecçôes intra-hospitalares as resultantes do uso de instrumentação endoscópica, de cateterismo urinário, venoso, de intervenção cirúrgica e de qualquer outro procedimento médico que fosse agressivo ao estado do paciente.

\section{Coleta de material}

Urina: foram coletadas após assepsia local e lavagem com água estéril, obtendo-se material do meio do jato urinário.

Secreções: foram coletadas através de zaragatoa umedecida em caldo nutriente.

Líquido cefalorraquidiano, líquido pleural, líquido ascítico: foram coletados e enviados de imediato ao laboratório.

Fezes: foram coletadas e enviadas de imediato ao laboratório ou conservadas em glicerina fosfatada.

Sangue: foram coletados e imediatamente plantados em meios específicos.

\section{Semeadura e identificação}

Para a urina, usamos $1 \mathrm{ml}$ da diluição $1: 100$ e $1: 1000$, que foi plantado em "pour plate" em meio de agar nutriente.
Em meio de tioglicolato e agar sangue foi plantado $0,1 \mathrm{ml}$ de urina não diluída.

As secreções foram plantadas em agar sangue, manitol salt agar e tioglicolato.

As fezes foram plantadas em SS. agar, em B. agar, manitol salt agar e tioglicolato. Só foram consideradas positivas para estafilococos, quando o exame direto revelava a presença de numerosos cocos Gram positivos isolados e agrupados e quando a cultura apresentava desenvolvimento rico (Mathias e col. ${ }^{26}$ ).

As amostras de sangue foram plantadas em tripticase soya broth e tioglicolato; o líquido ascítico, o cefalorraquidiano e o pleural foram plantados em agar sangue, manitol salt agar e tioglicolato. Seguimos uma metodologia bacteriana que nos conduziu à identificação da espécie bacteriana; apenas o estafilococo foi identificado através da fagotipagem.

Para a identificação das bactérias Gram negativas utilizaram-se as provas bioquímicas: produção do indol, utilização do citrato, do malonato, fermentação da lactose, da glucose, da manita, da sacarose, produção da urease, de H.s, descarboxilação da lisina e ornitina, redução do nitrato, pesquisa de motilidade, prova da fenilanina, de Voges-Proskauer e do vermelho de metila.

Para as Gram positivas foram usadas as provas da catalase, plasmocoagulase, fermentação da manita, teste da bacitracirua, sendo também usado meio com azul de metileno e com cloreto de sódio a $6.5 \%$.

\section{Antibiograma}

Usou-se a técnica de difusão em agar, empregando-se discos impregnados em antibióticos, segundo as recomendações de Bauer-Kirby com revisão de Rocha e col. ${ }^{37}$.

Os discos de antibióticos (Dfico, com exceção da fosfomicina fornecida pela 
IENDONCA, C. P. et al. - Infeções hospitalares no município de Araraquara, SP (Brasil). Rev. Salude puibl., S Paulo, 10:239-52, 1976.

Companhia Espanhola de Penicilina e Antibióticos) e suas respectivas concentrações foram as seguintes:



Através de zaragatoa embebida em cultura de algumas horas do germe a ser testado, foram semeadas placas de meio de Mueller-Hinton. Foram deixadas na estufa para secagem completa e depois distribuiram-se os discos. As placas permaneceram por duas horas. em temperatura ambiente, para a pré-difusão e depois foram incubadas a $37^{\circ} \mathrm{C}$.

A leitura foi feita após incubação de 18 a $24 \mathrm{~h}$, para todos os antibióticos, com exceção à meticilina que permaneceu por mais 24 horas (Hewitt e col. ${ }^{1 \pi}$ ), considerando-se sensíveis as zonas de inibição de $12 \mathrm{~mm}$ ou mais.

\section{R ES L L T A D O S}

Vesta pesquisa foram estudados 171 processos infecciosos intra-hospitalares. Não podemos afirmar ser exatamente esse o número de infecções que eclodiram nos hospitais, pois acreditamos que algumas devam ter escapado ao nosso controle.

Houve 139 infecções produzidas por um único germe; 26 por dois; 4 por três e duas por quatro germes. No total foram isolados 211 microrganismos, sendo $27.0 \%$ de bactérias Gram positivas e $73.0 \%$ de Gram negativas.

Na Tabela 1 encontramos os resultados dos microrganismos isolados das 171 in- fecções intra-hospitalares; na Tabela 2 observamos a correlação entre microrganismos e as condiçôes clínicas das infecções; e na tabela 3 encontramos a topografia das infecções clínicas.

Entre as várias infecções houve casos de otites, flegmão, meningite, septicemia, fístula abdominal, ferida bucal, colostomias, e outras. Observamos que o maior número de infecções foram as resultantes de intervenções cirúrgicas. A incidência de infecções urológicas foi elevada, mas. de modo geral, elas apareceram após instrumentação cirúrgica, endoscopia ou cateterismo prolongado.

Acreditamos que a incidência de infecções em pacientes queimados tenha sido maior em relação ao número dos internados; entretanto, consideramos infecções intra-hospitalares apenas aquelas adquiridas quando o paciente se internava nas primeiras horas do acidente.

Na Tabela 4 mostramos a incidência de dois ou mais germes nas diferentes condições clínicas das infecções intra-hospitalares. Nas figuras 1,2 e 3 mostramos a resistência dos microrganismos isolados frente aos antimicrobianos testados.

TABELA 1

Microrganismos causadores de infecçoes intra hospitalares

\begin{tabular}{l|rr}
\multicolumn{1}{c|}{ Germes } & n. & $\%$ \\
& & \\
\hline & & \\
Escherichia coli & 54 & 25,6 \\
Psendomonas aeruguosa & 51 & 24.2 \\
Estafilococo & 51 & 24,2 \\
Proteus sp. & 27 & 12,8 \\
Klebsiella-Enterobacter & 18 & 8,5 \\
Enterococo & 6 & 2.8 \\
Citrobacter & 3 & 1,4 \\
Serratia marcescens & 1 & 0,5 \\
& & \\
\hline & & \\
Total & 211 & 100,0 \\
\hline
\end{tabular}


MENDONÇA, C. P. et al. - Infecções hospitalares no municipio de Araraquara, SP (Brasil). Rev. Saúde públ., S. Paulo, 10:239-52, 1976.

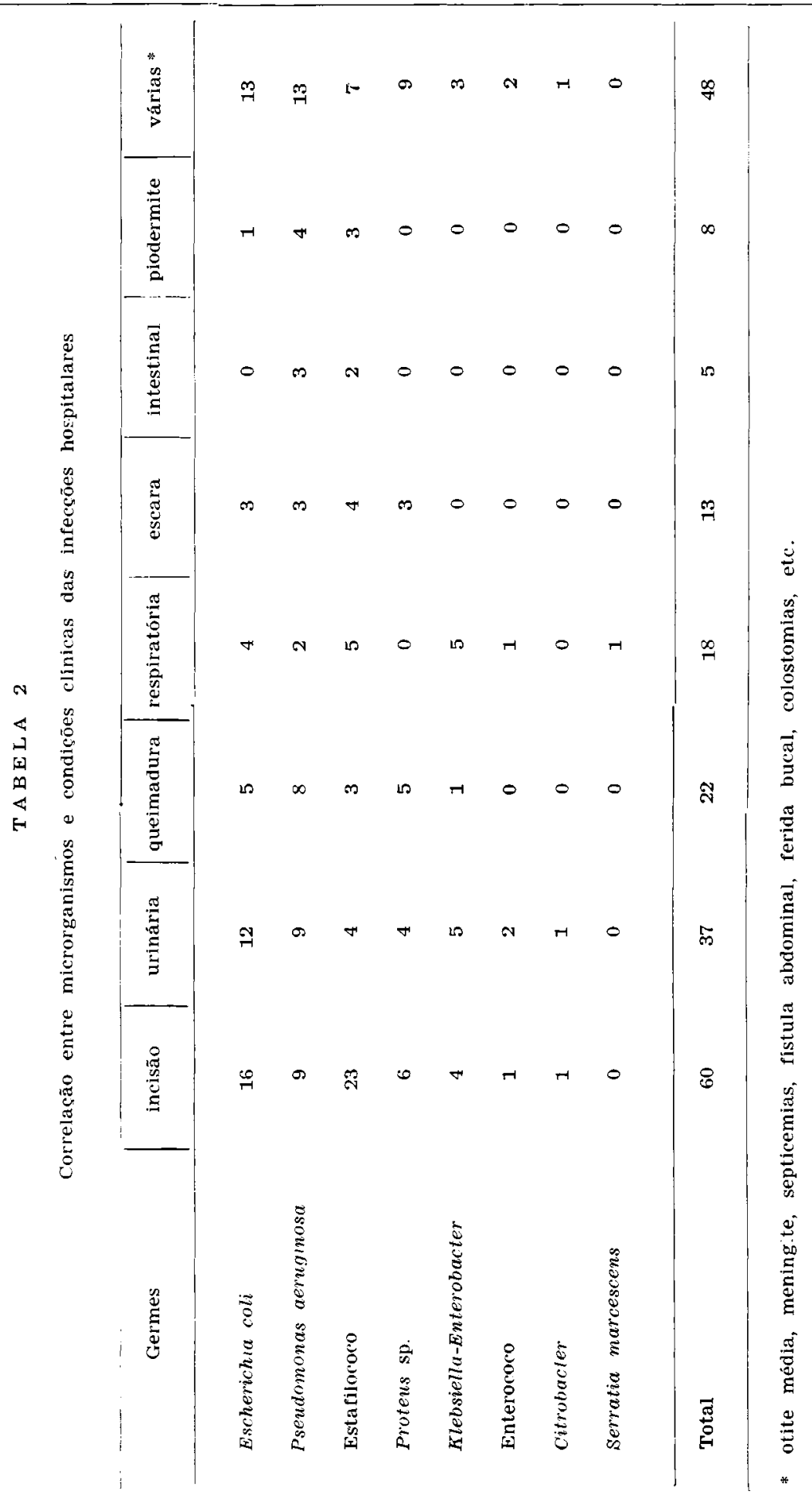


MENDONÇA, C. P. et al. - Infeccōes hospitalares no municipio de Araraquara, SP (Brasil). Rev. Saúde públ., S. Paulo, 10:239-52, 1976.

T A B ELA 3

Topografia das infecsões encontradas

\begin{tabular}{l|rr}
\multicolumn{1}{c}{ Infeção } & n.o & $\%$ \\
\hline Incisão & 50 & 29,3 \\
Queimadura & 16 & 9,4 \\
Respiratória & 14 & 8,2 \\
Urinária & 28 & 16,4 \\
Pele & 7 & 4,1 \\
Intestinal & 5 & 2,9 \\
Escara infectada & 13 & 7,6 \\
Várías & 38 & 22,2 \\
\hline Total & & \\
\hline
\end{tabular}

D I S C U S S A

Entre 171 infecções que se manifestaram em pacientes no decorrer de suas internações, verificamos que quase $2 / 3$ foram causadas por bactérias Gram negativas. Destas, houve um predomínio de Escherichia coli $(54-35,1 \%)$ e Pseudomonas aeruginosa $(51-33,1 \%)$ que contribuíram com a metade dos microrganismos isolados das infecções hospitalares.

Nossos resultados não são concordantes com os de Kessner e Lepper ${ }^{22}$, Price e Sleigh ${ }^{34}$, Selden e col. ${ }^{11}$, Hutzler e col. ${ }^{20}$, que afirmam que o grupo Klebsiella-Ente-

TABELA 4

Correlacão entre infeccỏes clinıcas e associacão de microrganismos causadores de infeccóes

\begin{tabular}{|c|c|}
\hline $\begin{array}{c}\text { Infeccōes clin cas } \\
\text { (origem) }\end{array}$ & Microrganismos \\
\hline incisão & $\begin{array}{l}\text { Esch. coli - Proteus sp. } \\
\text { Esch. coli - Klebs. Enterob. } \\
\text { Klebs. Enterob. - Pseudomonas } \\
\text { Klebs. Enterob. - Estafilococo } \\
\text { Esch. coll - Estafilococo } \\
\text { Enterococo - Pseudomonas }\end{array}$ \\
\hline queimadura & $\begin{array}{l}\text { Esch. coll - Proteus sp. } \\
\text { Klebs. Enterob. - Estafilorocos } \\
\text { Proteus sp. - Pseudomonas - Esch. coli }\end{array}$ \\
\hline respiratória & $\begin{array}{l}\text { Esch. coli - Estafilococo } \\
\text { Esch. coli - Enteirococo } \\
\text { Klebs. Enterob. - Pseudomonas }\end{array}$ \\
\hline urinária & $\begin{array}{l}\text { Esch. coll - Klebs. Enterob. } \\
\text { Esch. coli - Pseudomonas } \\
\text { Preudomonas - Klebs. Enterob. } \\
\text { Protens sp. - Pseudomonas - Estafilocoro } \\
\text { Proteus sp. - Pseudomonas - Enterococo - Estafilococo }\end{array}$ \\
\hline piodermite & Esch coll - Estafilococo \\
\hline várias & $\begin{array}{l}\text { Esch. coli - Proteus sp. } \\
\text { Klebs. Enterob. - Estafilococo } \\
\text { Esch. coll - Pseudomonas } \\
\text { Esch. coli - Pseudomonas - Estafilococo } \\
\text { Esch. coll - Pseudomonas - Estafilococo - Proteus sp. }\end{array}$ \\
\hline
\end{tabular}


MENDONCA, C. P. et al. - Infecções hospitalares no municipio de Araraquara, SP (Brasil). Rev. Saúde públ., S. Paulo, 10:239-52, 1976.

robacter tem causado maior número de infecções bacterianas em hospitais.

Em nossa casuística, o grupo KlebsiellaEnterobacter foi isolado em $18(11,7 \%)$ do total das bactérias Gram negativas e por 10 vezes apareceu ao lado de outros germes, causando infecções; causou, no entanto, cinco processos infecciosos em vias respiratórias, dos quais dois foram considerados graves, com evolução para o óbito.

Scheckler e col. ${ }^{40}$, demonstaram ter achado $8,8 \%$ de Klebsiella e $6,2 \%$ de Enterobacter, o que se aproxima bem dos rossos achados, visto que o número de bactérias Gram negativas isoladas foi de $75,4 \%$ e de bactérias Gram positivas foi de $24,6 \%$.

Hutzler e col. ${ }^{20}$, citam que na revisão nacional dos EUA, entre janeiro e março de 1970, foram encontrados: Escherichia coli, 20,2\%; estafilococos, 16,1\%; Proteus, $10,9 \%$; Pseudomonas, $8,9 \%$; Klebsiella, $6,5 \%$; Enterobacter, $4,5 \%$; enterococo, $5,3 \%$ e Serratia, $0,9 \%$, causando infecçōes intra-hospitalares.

Podemos dizer que até há bem pouco tempo havia predominância de bactérias Gram positivas em um dos hospitais exarinados. Ademais, vários surtos de esta-

TABELA 5

Resistência dos microrganismos causadores de infeccões intra hospitalares frente a 10 antimicrobianos

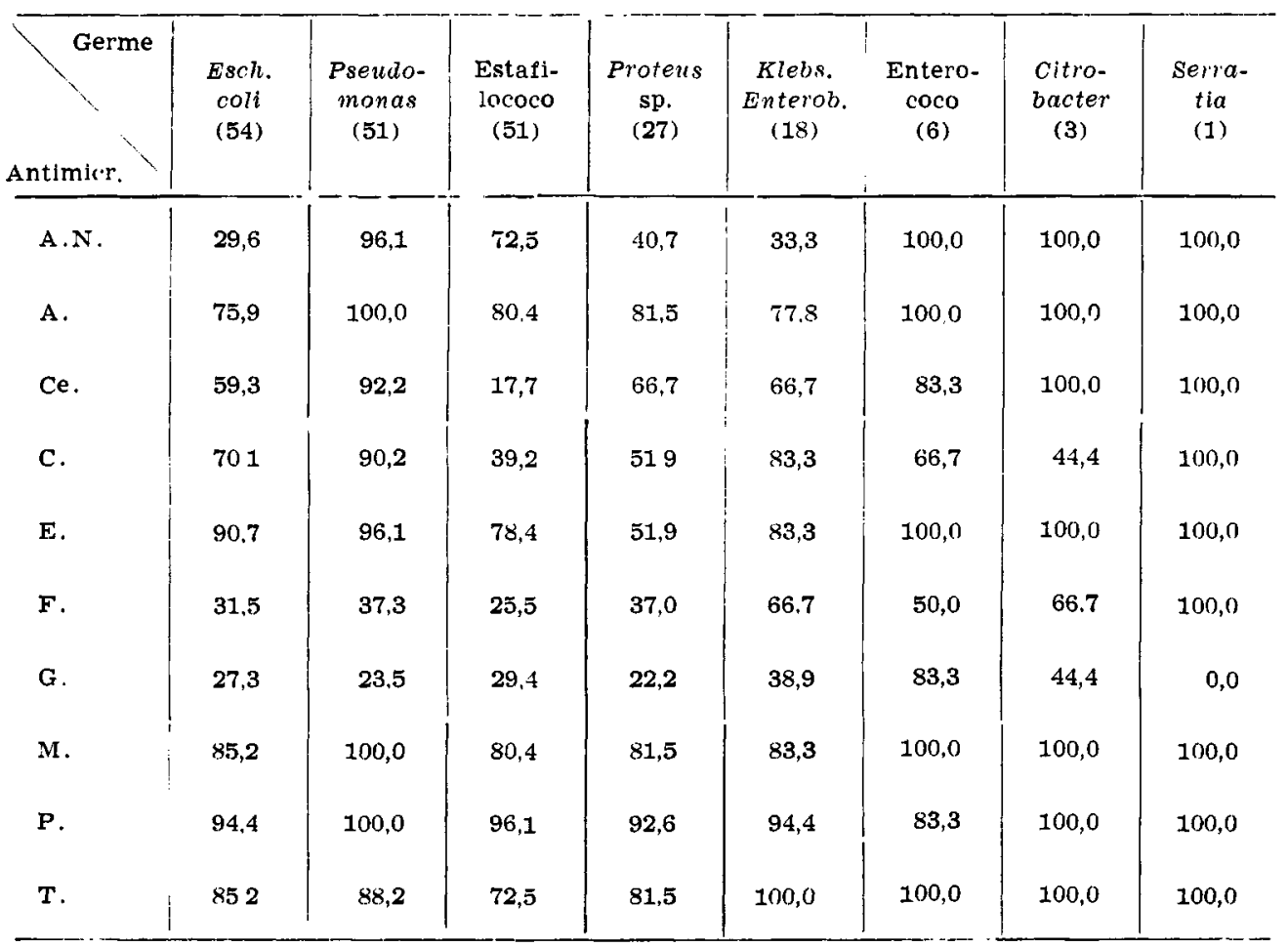

A.N. Ácido nalidíxico - A. Ampicilina - Ce. Cefalotina - C. Cloranfenicol - E. Estreptomicina - F. Fosfomicina - G. Gentamicina - M. Meticilina - P. Penicilina G. - T. Tetraciclina - ( ) número de germes isolados. 
MENDONÇA, C. P. et al. - Infecços hospitalares no município de Araraquara, SP (Brasil). Rev. Saúde puibl., S. Paulo, 10:239-52, 1976.

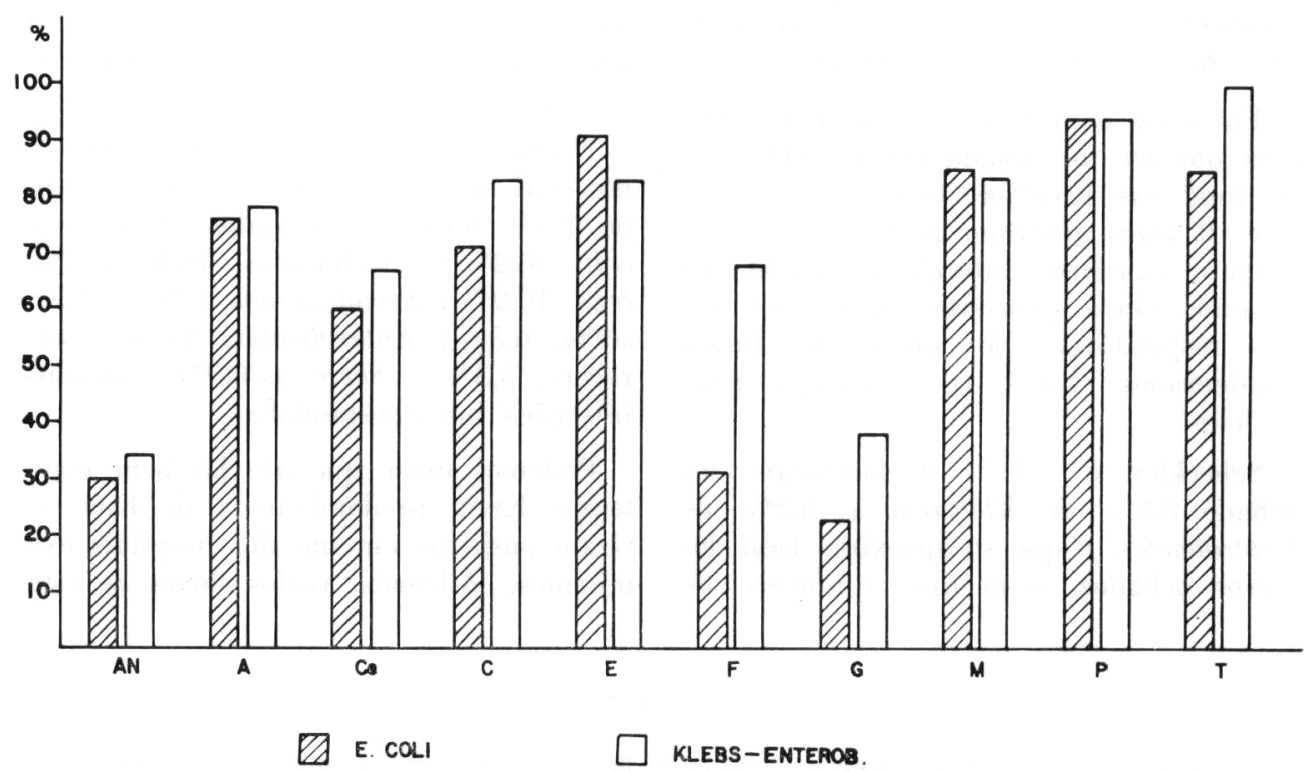

Fig. 1 - Resistencia das amostras de Escherichia coli e Klebsiella Enterobacter frente a 10 antimicrobianos.

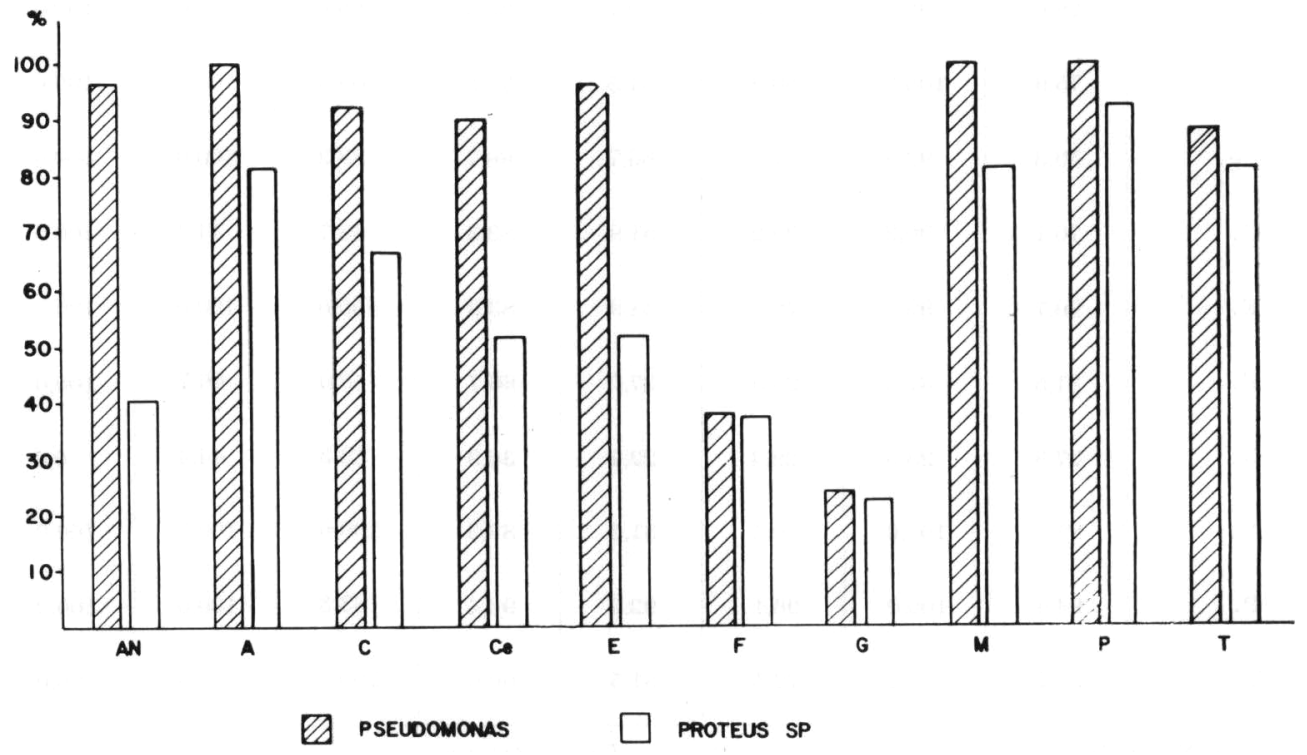

Fig 2 - Resistencia das amostras de Pseudomonas e Proteus sp. frente a 10 antimicrobianos. 
MENDONCA, C. P. et al. - Infecçóes hospitalares no municipio de Araraquara, SP (Brasil). Rev. Saúde públ., S. Paulo, 10:239-52, 1976.

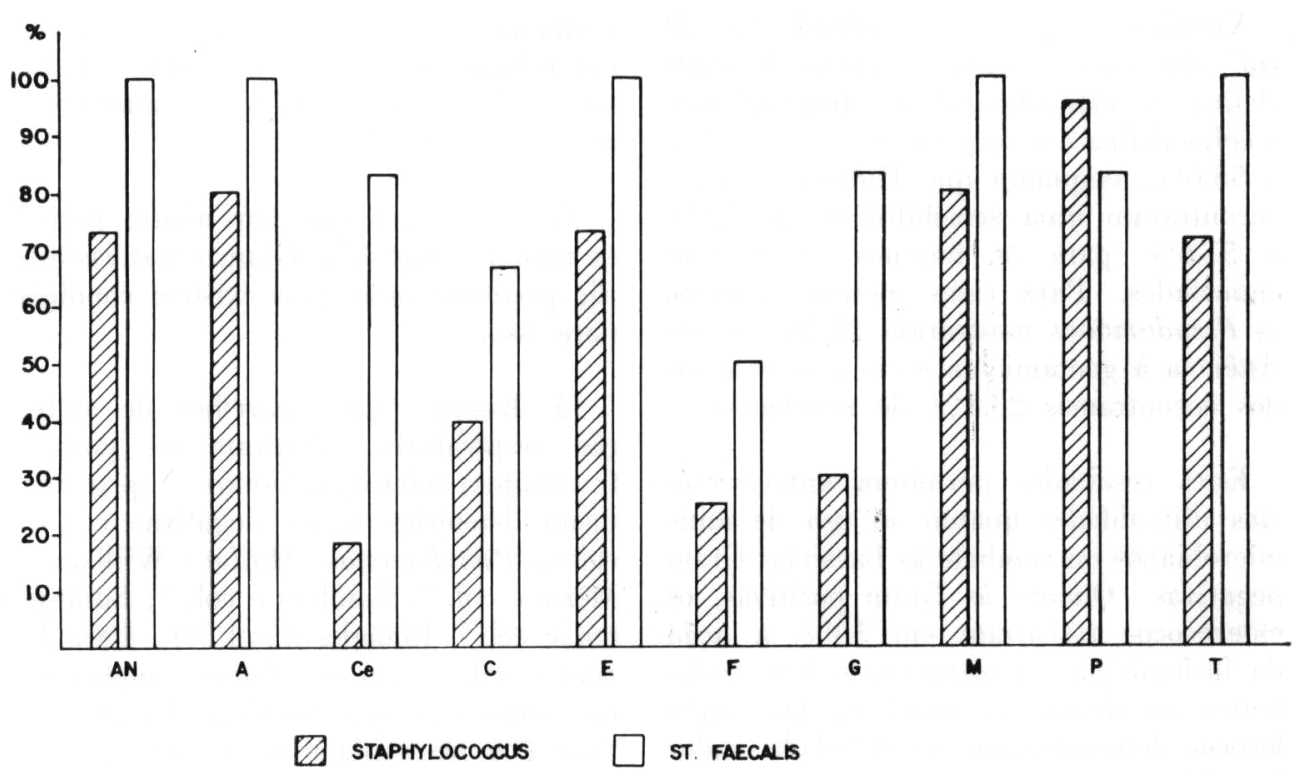

Fig. 3 - Resistencia das amostras de Staphylococcus aureus e Streptococcus faecalis frente a 10 antimicroblanos.

filococos fizeram-se notar em berçário, de um dos hospitais, ocasião em que se passou a usar o hexaclorofeno para evitar a colonização desse microrganismo. Nessa ocasião houve implantação da $P_{\text {seudomo- }}$ nas aeruginosa (Falcão e col. ${ }^{12}$ ) que facilmente se disseminou por todo o hospital.

Neste estudo ela aparece com maior frequiência em infecções cirúrgicas, fazendo parte de infecções múltiplas 14 vezes.

Moore e Forman ${ }^{31}$, Ayliffe e col. ${ }^{1}$, Tinne e col. ${ }^{49}$, Stamm ${ }^{*}$, citam surtos de Pseudomonas em centros cirúrgicos.

0 estafilococo, em nossa casuística, ainda é o maior agente causal de infecções, principalmente em incisão cirúrgica, aparecendo em 12 infecçôes, associado com outros germes, principalmente Escherichia coli.

Verificamos que as bactérias isoladas apresentam alto nível de resistência aos antibióticos testados. A gentamicina apresentou melhor resultado "in vitro" para as hactérias Gram negativas, coincidindo com os achados de Hutzler e col. ${ }^{12}$.

Loriam e Toph ${ }^{2.1}$, referem-se ao aumento de resistência das bactérias Gram negativas à ampicilina e a tetraciclina, com c que concordamos, pois, em nossos achados, a menor resistência foi de $61,1 \%$ e $75,9 \%$ para a tetraciclina e a ampicilina. respectivamente.

A ampicilina foi sensivel a $13(24,1 \%)$ amostras de Escherichia coli e a 4 . $(22,2 \%)$ amostras de Klebsiella-Enterobacter. O cloranfenicol mostrou-se ativo para $14(25,9 \%)$ amostras de Escherichia coli e a $13(48,2 \%)$ de Proteus sp. A estreptomicina mostrou-se sensível a 13 amostras $(48,2 \%)$ de Proteus sp., enquanto o ácido nalidíxico apresentou sensibilidade a 16 amostras $(59,3 \%)$ do mesmo germe.

* Comunicação pessoal. 
MENDONCA, C. P. et al. - Infecções hospitalares no municipio de Araraquara, SP (Brasil). Rev. Saúde puibl., S. Paulo, 10:239-52, 1976.

Verificamos que a sensibilidade "in vitro" dos vários Gram negativos à tetraciclina, ao cloranfenicol, à estreptomicina, à cefaloridina e à ampicilina foi de $24,1 \%$ a $55,6 \%$, enquanto que Hutzler e col. ${ }^{20}$ encontraram uma sensibilidade de $5,4 \%$ a $51,4 \%$ para os mesmos antibióticos єnunciados. Para esses mesmos autores, as Pseudomonas mostraram $15,4 \%$ de resistência à gentamicina e em nossos achados encontramos $23,5 \%$ de resistência.

Estes resultados permitem antever sérias dificuldades quanto ao uso de antimicrobianos no combate às bactérias Gram negativas. Quanto às Gram positivas, os enterococos resistiram em $50 \%$ à ação da fosfomicina e mostraram-se bem resistentes aos demais antibióticos. Os estafilococos demonstraram sensibilidade maior à cefalotina, à fosfomicina e à gentamicina, com $82,4 \%, 74,5 \%$ e $70,6 \%$, respectivamente.

Nossa preocupação, ao realizarmos este estudo, foi a de utilizar técnicas que pernitissem obter apenas a especiação bacteriana. Não nos preocupamos com a identificação mais específica dos microrganismos isolados, a não ser com o estafilococo, porquanto, através de numerosos trabalhos (Kennedy e col. ${ }^{21}$, Spencer e col. ${ }^{46}$, Cooke e col. ${ }^{8}$, Shooter e col. ${ }^{44,45}$, Weil e col. ${ }^{53}$, Dans e col. ${ }^{9}$, Falcão e col. ${ }^{12}$, e Lorian e col. ${ }^{24}$ ), verificamos que, em levantamentos semelhantes a obtenção de resultados epidemiológicos das infecções causadas por bactérias Gram negativas não apresentaram conclusões definidas.

Realizamos a fagotipagem das amostras de estafilococos no Laboratório de Microbiologia e Imunologia da Faculdade de Medicina de Ribeirão Preto da USP. Encontramos $21(41,2 \%)$ amostras não tipáveis, apesar de se ter usado o conjunto básico internacional mais os fagos experimentais $86,89,90,92,94,95$ e 96. Houve pequena predominância do fagogrupo III com $10(19,6 \%)$ amostras. $\mathrm{Na}$ realidade, temos de considerar a situação em relação ao estafilococo como bastante séria, visto que também foi multirresistente aos antibióticos.

Tudo faz crer que por algum período de tempo as bactérias Gram negativas estarão predominando, pois existem condições para isso.

Já dissemos que aparelhos de sustenção respiratória colonizam - portanto transmitem microrganiosmos - principalmente bactérias Gram negativas e entre elas as Pseudomonas (Moffet e Williams ${ }^{30}$, Mertz e col. ${ }^{29}$, Sanders e col. ${ }^{38}$, Babinghton e col. ${ }^{2}$, Rhoades e col. ${ }^{36}$ ). Para Lorian e col. ${ }^{2 \pm}$, um dos fatores importantes na colonização das bactérias Gram negativas é a necessidade de manter grau de umidade na superfície corpórea de alguns pacientes.

Temos de considerar que os antimicrobianos têm uma ação mais determinante sobre as bactérias Gram positivas (Light e col. ${ }^{23}$, Datta ${ }^{10}$, Scheckler e Bennett ${ }^{39}$ ), os germicidas são mais eficientes para a erradicação das Gram positivas (Light e col. ${ }^{23}$, Bruun ${ }^{5}$, Burdon e Whitby ${ }^{6}$ ). Temos de considerar também a facilidade que as bactérias Gram negativas têm de sobreviver no meio ambiente, como em ralos, pias, água, borbulhamento de oxigênio (Thomas e col. ${ }^{51}$, Falcão e col. ${ }^{12}$ ) e às vezes, até em produtos manipulados para uso de pacientes.

Hutzler e col. ${ }^{19}$, Felts e col. ${ }^{13}$ demonstraram que pacientes que receberam antimicrobianos durante a internação tornaram-se portadores de bactérias Gram negativas, em proporção maior do que as não medicadas com antimicrobianos.

Stratford e col. ${ }^{48}$ afirmam que a colonização de bactérias Gram negativas se faz mais facilmente em pacientes hospitalizados em condições graves. Hutzler ${ }^{18}$, estudando os portadores cutâneos, verifi- 
MENDONCA, C. P. et al. - Infeccões hospitalares no município de Araraquara, SP (Brasil). Rev. Saude puibl., S. Paulo, 10:239-52, 1976.

cou que durante a internação havia um aumento da flora bacteriana Gram negativa, sem que os pacientes estivessem em más condições de saúde.

\section{CON C L U SOE S}

1 - Dos 211 microrganismos isolados. $27,0 \%$ foram bactérias Gram positivas e $73.0 \%$ bactérias Gram negativas.

2 - A incidência maior de infecções intra-hospitalares recaiu sobre incisão cirúrgica. com $29,3 \%$.

3 - Dos processos infecciosos. 32 foram causados por dois ou mais tipos de germes.

4 - Verificou-se nível elevado de resistência a quase todos os antimicrobianos, quer pelas bactérias Gram positivas ou negativas.

5 - A Gentamicina, de um modo geral, foi o antibiótico que melhor se revelou em nossa casuística para as bactérias Gram negativas.

6 - Os estafilococos apresentaram melhor sensibilidade frente à cefaloridina, à fosfomicina e à gentamicina.
7 - Os estafilococos. embora apresentando menor incidência em relação a cutros estudos aqui realizados, passou a epresentar maior resistência aos antibióticos e menor proporção de amostras lisadas pelos fagos do conjunto básico e experimentais.

8 - Os resultados permitem sugerir que medidas enérgicas devam ser tomadas a fim de evitar males ainda maiores.

\section{A G A D E C I N E N T O S}

Ao Prof. Dr. Carlos Solé-Vernin, Prof. adjunto do Departamento de Parasitologia, Microbiologia e Imunologia da Faculdade de Medicina de Ribeirão Preto da LSP; à Profa. Dra. Ana Maria Lithida Tanaka e à técnica Olga Coelho de Castro, do Laboratório de Cocos patogênicos da Faculdade de Medicina de Ribeirão Preto da LiSP; ao Erminio Mantovanelli e Maria Julia do Carmo Zamboni, da Faculdade de Farmácia e Odontologia de Araraquara, assim como a todos que direta ou indiretamente tem colaborado para o estudo a que nos dedicamos.

Mendonça, C P. et al. - [study of infections acquired in hospitals in Araraquara (Brazll)]. Rev. Saúde públ., S. Paulo, 10:239-52, 1976.

SLMMARY: The ethiology of the infections acquired in the City Hospitals and the behaviour of isolated bacteria by means of ten (10) antimicrobians, were demonstrated. The bacteriologic methodology was followed which conducted to the identification only of the bacterian species, except Stafilococci that were individualized through phagotyping. A hundred and seventy one (171) infectious processes in hospitals were collected from september, 197. to May, 1975 from these processes, two hundred and eleven (211) microorganisms were isolated, $72.99 \%$ being Gram negative and $27.05 \%$ Gram positive. A high level of antibiotic resistence was verified. The Gram negative bacteria presented smaller resistence to Gentamicine and the Gram positive, a better sensibility to Cefalotine, Fosfomicine and Gentamicine. An analysis of the results allows us to foresee serious difficulties as regards the action of antimicrobians on bacteria, and also the intense spread of Gram negative bacteria, specially Escherichia coli and Pseudomonas.

UNITERMS: Cross infections, Araraquara (Brazil). 
MENDONCA, C. P. et al. - Infecçōes hospitalares no municipio de Araraquara, SP (Brasil). Rev. Saúde públ., S. Paulo, 10:239-52, 1976.

\section{REFERENCIAS BIBLIOGRAFICAS}

1. AYLIFFE, G.A.J. et al. - Postoperative infection with Pseudomonas aerugino. s $a$ in an EYE Hospital. Lancet, 1: 1113-7, 1966.

2. BABINGHTON, P.C.B. et al. - Retrogradespread of organism from ventilator to patient via the experatory limb. Lancet, 1:61-2, 1971.

3. BANKS, D.C. - Infection from intravenous catheters. Lancet, $1: 443-5,1970$.

4. BARRETT, F.F. et al. - Infection and antibiotic use at Boston City Hospital (Febenany, 1967). New Engl. J. Med., 278:5-9, 1968 .

5. BRUUN, J.N. - Post operative wound infection. Predisposing factors and the effect of reduction in the dissemination of Staphylococci. Acta med scand., (Supl. 514):1-89, 1970.

6. BURDON, D.W. \& WHITBY, J.L. Contamination of Hospital desinfectants with Pseudomonas species. Brit. med. J., 2:153-5, 1967.

7. CASWELL, H.T. et al. - A ten year study Staphylococcal disease. Surveillance control and prevention of Hospital infection, 1956 to 1965 Arch. environm. Hlth, 17:221-4, 1968

8. COOKE, E.M. et al, - Changing faecal populations of Escherichia coli in Hospital medical patients. Brit. med. J., 4:593-5, 1969

9. DANS, P.E. et al. - Klebsiella Enterobacter at Boston City Hospital 1967. Arch. intern. Med., 125:94-101, 1970.

10. DATTA, N. - Drug resistance and $R$ factors in the bowel bacteria of London patients before and after admission to Hospital. Brit. med. J., 2: 407-11, 1969.

11. DUPONT, H.L. \& SPINK, W.W. - Infection due to Gram negative organisms: an analysis of 860 patients with bacteriemia at the University of Minnesota Medical Center, 19581966. Medicine, Baltimore, 48:30782, 1969.
12. FALCAO, D.P. et al, - Nursery outbreak of severe diarrhoea due to multiple strains of Pseudomonas aeruginosa. Lancet, 2:38-40, 1972 .

13. FELTS, S.K. et al. - Sepsis caused, by contaminated intravenous fluids Epidemiologic, Clinical and Laboratory investigation of an outbreak in one Hospital. Ann. intern. med., 77:88190, 1972

14. FINLAND, M. et al. - Ocurrence of serious bacterial infections since introductions of antibacterial agents. J. Amer. med. Ass., Chicago, 170: 2188-97, 1959.

15. FREID, M.A. \& VOSTI, K.C. - The importance of underlying disease in patients with Gram negative bacteriemia. Arch, intern. Med., 121:41823,1968 .

16. GARDNER, P. \& SMTH, D.H. - Studies on the epidemiology of resistance (R) factors. I. Analysis of Klebsiella isolate in a general hospitals. II. A prospective study of $R$ factors transfer in the host. Ann. intern. Med, 71:1-8, 1969.

17. HEWITT, J.H. et al, - The detection of Methicillin resistance in Staphy. lococcus aureus. J. med. Microbiol. 2:443-55, 1969.

18. HUTZLER, R.U. - Staphylococcus aureus e Bactérias Gram negativas em pacientes hospitalizados. São Paulo, 1971. [Tese de doutoramento - Faculdade de Medicina da USP].

19. HUTzLER, R.U. et al. - Colonização de doentes hospitalizados por Staphylococcus aureus e bactérias Gram negativas. Rev. Microbiol., 3:179-89, 1972 .

20. HUTZLER, R.U. et al, - Aspectos microbiologicos de infecçóes hospitalares. Rev. Hosp. Clin. Fac. Med. S. Paulo, 28(Supl.):18-30, 1973.

21. KENNEDY, R.P. et al. - Studies on the epidemiology of Escherichia coli infections. IV. Ividence for a nosocomial flora. J. clin. Invest., 44: 193-201, 1965. 
MENDONCA, C. P. et al. - Infecçóes hospltalares no municiplo de Araraquara, SP (Brasil). Rev. Saude públ., S. Paulo, 10:239-52, 1976.

22. KESSNER, D.M. \& LEPPER, M.H. Epidemiologic studies of Gram negative bacilli in the Hospital an community. Amer. J. Epidemiol., 85: $43-60,1967$.

23. LIGHT, I.J. et al. - Ecological relation between Staphylococcus aureus and $P$ seudomonas in a nursery population. New Engl. J. Med., 278:1243-7, 1968.

24. LORIAN, V. \& TOPF, B. - Microblology of nosocomial infections. Arch. intern. Med., 130:104-10, 1972.

25. MARTIN, C.M. - A National bacteremia registry. J. infect. Dis., Chicago, 120:495-6, 1969.

26. MATHIAS, J.R. et al, - Staphylococcus aureus in the faeces of Hospital patients. Lancet, 272:1172-3, 1957.

27. MC KEE, W.M. et al. - Anal carriage as the probable source of strepto. coccal epidemic. Lancet, 2:1007-9, 1966

28. MC NAMARA, M.J. et al. - A study of the bacteriologic patterns of hospital infections. Ann. intern. Med. 66:480-8, 1967 .

29. MERTZ, J.J. et al. - Hospital outbreak of Klebsiella pneumoniae from inhalation therapy with contaminater aerosol solutions, Amer, Rev, resp. Dis., 95:454-60, 1967.

30. MOFFET, H. \& WILLIAMS, T. - Bacteria recovered from distiled water and inhalation therapy equipment. Amer. J. Dis. Child., 114:7-12, 1967.

31. MOORE, B. \& FORMAN, A. - An outbreak of urinary Pseudomonas aeruginosa infections acquired during urological operations. Lancet, 2: 929-31, 1966 .

32. NOBLE, W.C. - An epidemic of Streptococcal infections in a skin hospltal. Brit. J. Derm, 81:259-63, 1969.

33. PEQUIGNOT, $H$, et al. - La pathologie infectieuse dans un servise de médicine generale. Sem. Hop. Paris, 44:2587-99, 1968 .

34. PRICE, D.J.W. \& SLEIGH, J.D. Control of infection due to Klebsiella aerogenes in a neurosurgical unit by with drawal of all antibiotice. Lancet, 2:1213-5, 1970 .

35. RAMMELKAMP JR., C.H. et al, Transmission of Streptococcal and Staphylococcal infection. Ann, intern. Med., 60:753-8, 1969.

36. RHOADES, E.R. et al. - Contamination of ultrasonic nebulization equipment with Gram negative bactéria. Arch. intern. Med., 127:228-32, 1971.

37. ROCHA, H. et al. - Antiblogramas. Rev. Microbiol., 3:51-60, 1972.

38. SANDERS JR., C.V. et al. - Serratie marcescens infections from inhalation therapy medications: nosocomial outbreak. Ann. intern. Med. $73: 15-21,1970$.

39. SCHECKLER, W.E. \& BENNETT, J.V. - Antibiótic usage in seven com. munity hospitals. J. Amer. med. Ass., 213:264-7, 1970.

40. SCHECKLER, W.E. et al. - apud HUTZLER, R.U. et al. ${ }^{20}$.

41. SELDEN, R. et al. - Nosocomial klebsiella infections: Intestinal Colonization as a reservoir. Ann. intern. Med., 74:657-64, 1971.

42. SHALLARD, M.A. \& WILLIAMS, A.L. - A study of the carriage of Gram negative bacilli in a ward for newborn babies in hospital. Med. J. A ust., 1:540-2, 1965.

43. SHALLARD, M.A. \& WILLIAMS, A.L. - Studies on a Gram negative bacllli in a ward for newborn bables. Med. J. Aust., 2:455-9, 1966.

44. SHOOTER, R.A. et al. - Food and medicaments as possible sources of strains of Pseudomonas aeruginosa Lancet, 1:1227-9, 1969.

45. SHOOTER, R.A. et al. - Isolation of Escherichia coli, Pseudomonas aeruginosa and Klebsiella from food in hospitals, canteens and schools. Lancet, 2:390-2, 1971 . 
MENDONCA, C. P. et al. - Infeccões hospitalares no municipio de Araraquara, SP (Brasil). Rev. Saúde puibl., S. Paulo, 10:239-52, 1976.

46. SPENCER, A.G, et aI. - BETTLEHEIM, K.A. \& TAYLOR, J. - Escherichia coli serotypes in urinari tract infection in a medical ward. Lancet, 2 : $839-42,1968$.

47. SPITTEL JR., J.A. \& NICHOLS, D.R. - Bacteremia owing to Gram negative bacilli; experience in the treatment of 137 patients in a 15 year period. Ann. intern. Med., 44:30215, 1956.

48. STRATFORD, B. et al. - Alteration of superficial bacterial flora in severely ill patient. Lancet, 1:68, 1968.

49. TINNE, J.E. et a1. - Cross infection by Pseudomonas aeruginosa as a hozard of intensive surgery. Brit. med. J, 4:313-5, 1967 .

50. THOBURN, R. et al. - Infection acquired by hospitalized patients. An analysis of the overall problem. Arch. intern. Med., 121:1-10, 1968.

51. THOMAS, M.E.M. et al. - Contamination of an operating theatre by Gram negative bacteria. Examination of water suplies, cleaning methods and wound infections. J. $H y g$., London, 70:63-73, 1972 .
52. WAISBREN, B.A. - Bacteremia due to Gram negative bacilli other than the Salmonella. A clinical and therapeutic study. Arch. intern. Med, 88:467-88, 1951 .

53. WEIL, A.S. et al. - Nosocomial infections with Klebsiella type 25. New Engl. J. Med., 275:17-22, 1966.

54. WILLIAMS, R.E.O. et al, - Isolation for the control of Staphylococcus infection in surgical wards. Brit. med. $J ., 2: 275-82,1962$.

55. WILliams, R.E.O. - Airborne Staphylococci in the surgical ward. J. Hyg., London, 65:207-17, 1967.

56. WINTON, F.W. \& KEAY, A.J. - Bacteria in a hospital nursery laboratory and clinical studies. J. Hyg., London, $66: 325-42$, 1968 .

57. YOW, E.M. - Clinical significance of rising incidence of infections due to Gram negative bacilli. Postgrad. Med., 17:413-9, 1955.

Recebido para publicasão em 19/12/1975 A provado para publicacáo em 12/03/1976 